\title{
Lean thinking in total nursing care for mechanically ventilated patients: A new concept in ICU
}

\author{
Sally Mohammed Farghaly ${ }^{1,2}$, Fatma Refaat Ahmed*1 \\ ${ }^{1}$ Nursing Administration, Faculty of Nursing, Alexandria University, Alexandria, Egypt \\ ${ }^{2}$ Nursing Management and Education Department, College of Nursing, Princess Nourah bint Abdulrahman University Riyadh, \\ Saudi Arabia
}

Received: May 23, 2019

Accepted: August 19, 2019

Online Published: September 16, 2019

DOI: $10.5430 /$ jnep.v10n1p1

URL: https://doi.org/10.5430/jnep.v10n1p1

\begin{abstract}
Background: Lean approach is one of the coming revolutions for a better, improved, high-value-based care to maximize the benefit from nursing care activities. Additionally, it can shorten the mechanical ventilation duration and the total intensive care unit stay with a time and cost effective process. Lean is an improvement strategy based on the concept of eliminating the waste and creation of value-added care practices to the patients. Applying lean strategy for mechanically ventilated patients requires critical evaluation of all steps of the care to identify which add value and which do not.

Methods: A descriptive research design was used in the current study and two tools were used for data collection in this study: "Lean assessment observational checklist of total care for mechanically ventilated patients", and "Critical care nurses' self-report about waste during total care of mechanically ventilated patients".

Results: The differences between value added and non-value added care practice items were not statistically significant in ventilator and patient care practices items $(p=.232$ and .884$)$ respectively, while there was no statistical difference between the value added and non-value added care practice items in tube care. The differences between the time consumed in all care practices items were statistically significant $(p<.001)$. According to the nurses' self-report, direct care for patients was ranked as the first care category that can increase the cost and effort followed by the indirect care category.

Conclusions: Not all care items for mechanically ventilated patients have been added value to the patients. Waste outcomes as reported by nurses resulted in increase their efforts, time of care, in addition to increase the cost of care.
\end{abstract}

Key Words: Evaluation, Lean, Mechanically ill patients, Lean thinking, Total nursing care

\section{INTRODUCTION}

Mechanically ventilated patients (MVPs) spend days and even months on the mechanical ventilator. Mechanical ventilation, though potentially lifesaving, is capable of producing adverse events, some of which may in themselves be life threatening. ${ }^{[1]}$ Usually, those patients have one of three trajectories; survival with recovery, survival without recovery, or non-survival. Therefore, optimizing the care provided for MVPs is an emerging and challenging target.
Improving the care for these patients is always of concern for the caregivers especially critical care nurses. Direct care is not the only responsibility of critical care nurses toward MVPs, there are other multiple aspects of the provided care. The indirect patients' care practices performed away from them, including giving reports, communication with the team, gathering supplies, preparing equipment, and seeking consultation. ${ }^{[2,3]}$ Direct and indirect care together with other practices such as unit related practices and personal practices

*Correspondence: Fatma Refaat Ahmed; Email: fatmarefaat1312@ gmail.com; Address: Faculty of Nursing, Alexandria University, Edmon Fremon St. Smouha, Alexandria, Egypt 
are occupying the time the critical care nurses spend with MVPs. ${ }^{[3]}$ Therefore, it is necessary to assign all the resources within the care process according to time and demand ${ }^{[4]}$ and exclude any intervention provides no-value for MVPs to get the optimum value of all care practices, decreasing the mechanical ventilation and intensive care units (ICUs) beds occupation rate and the total cost of ICU stay. ${ }^{[5,6]}$

In an effort to standardize competency of the care for MVPs, new care concepts have been proposed to ICU community to maximize the value of technical and non-technical components of patients' care. ${ }^{[7]}$ Lean is a systematic approach enterprise that aiming firstly to identifying waste and then eliminating these waste (non-value-added activities). Lean is an improvement strategy based on the concept of eliminating the waste and creation of value-added care practices to the patients. Lean philosophy was derived from the Toyota model, it focuses on how efficiently resources are being used and include only what add value for the customers' in every process. Lean allows evaluating the care processes to eliminate waste through continuous analysis of the care steps. Applying lean strategy for MVPs during their ICU stay needs critical evaluation of all steps of the care to determine which add value and which do not. ${ }^{[8,9]}$

In healthcare, value-added is "any activity that directly meets the needs of a patient" such as the action of a staff nurse completing gastric feeding and medications administration According to the Japanese, the non-value-added activities are classified into three types, Muda, Mura, and Muri. ${ }^{[10]}$

Muda is a non- value adding which means waste. Unfortunately, there are eight wasteful care items that are performed by critical care nurses in the daily care practices for MVPs in the form of defects, overproduction, waiting times, wasted talent, not needed transportation, inventory, excessive motion, and excess processing. Over-production in which misuse of ICU resources such as waste in using advanced technology, equipment and drugs, waiting times; there is loss of time corresponding to waiting time, prepare equipment, wait for a consultant order, or receive essentials supplies, defects; represents all categories of errors, MVPs are at a high risk for iatrogenic errors such as medication errors, lack of standardized care, or failure to implement the intended treatment outcomes. ${ }^{[1,12]}$ In addition to excessive movement; referred to any unnecessary movement of critical care nurses to complete a task or searching for supplies, not needed transport; as frequent and repeated shifts in materials or patients, due to poor planning of activities, layout design, or scheduling. Excessive stocks; related to increasing cost, due to use of spaces, stocks, or supplies, over-processing; is the efforts that have no contribution in achieving the outcomes of the health care services to MVPs, such as unnecessary duplication of certain procedures and wasted talent; in which the waste is presented as inappropriate use of human abilities (physical, cognitive, or creative). ${ }^{[3,11]}$

Mura is another type of waste which means unevenness. Unevenness is presented when there is more work than the staff or equipment can handle, or when there is a lack of work. It results from the irregular schedule and when there is a shortage in staff, this can lead to errors during the work which causes dissatisfaction in the care provided to patients. Muri means overburden staff or equipment pushing staff or equipment beyond limits results in safety and quality problems. ${ }^{[13,14]}$

Legally and ethically, nursing acts should be committed to MVPs in a manner that results in no harm, no waste care practices. ${ }^{[1]}$ Indeed, critical care nurses should be value oriented to all care practices for MVPs in which they are challenged with providing safe, efficient and effective care practices. ${ }^{[15]}$ However, lean evaluation is the step that precedes the lean implementation and sustainability process. Value stream map (VSM) is a lean strategy that documents the time for each process step and helps critical care nurses determining which steps in the care process add value to MVPs and which steps take up resources and time and incur cost without adding value. ${ }^{[14,16]}$

Despite the lean concept have been handled in several international researches, ${ }^{[4,6,9-11,17]}$ none of them studied the lean in specific care process provided for the critically ill patients. Moreover, to our knowledge, such studies remain limited in Egypt. Thus, to guarantee the application of such care approach and fully embrace the ethically sound, and evidence-based recommendations for the purpose of efficiently de-adopt wasteful practices, it is logic to firstly evaluate the lean in the total care provided for that population.

\subsection{Aim of the study}

To assess the value added and non-value added practices in the total nursing care for mechanically ventilated patients.

\subsection{Research question}

What is the value added and non-value added care practices in the total nursing care of mechanically ventilated patients?

\section{MATERIALS AND METHOD}

\subsection{Research design}

A descriptive research design was used for this study.

\subsection{Setting}

This study was carried out in two general ICUs in a selected governmental hospital in Alexandria- Egypt. Procedures 
and care policies regarding the total care of mechanically ventilated patients were equally applied in both ICUs.

\subsection{Subjects}

The sample comprised of 60 nurses selected conveniently from the two ICUs. Professional, technical, and intern critical care nurses who were involved in providing total nursing care of MVPs were included in this study throughout the different three shifts. The study sample size was calculated by power analysis (Epi-info program); population size $=75$, acceptable error $=10 \%$, expected frequency $=50 \%$, confidence coefficient $=99 \%$ and minimum sample size $=52$.

\subsection{Measures}

Two tools were used for data collection; "Lean evaluation observational checklist of total care for mechanically ventilated patients" and "Critical care nurses' self-report about waste during total care of mechanically ventilated patients".

Tool 1: Lean evaluation observational checklist of total care for mechanically ventilated patients

This tool was developed by the researches after reviewing the relevant literature and comprises several items to describe the nursing interventions that should be provided on a daily basis for MVPs, which are categorized as ventilator care, tube care, and patient care practices.

Ventilator related care practices checklist ${ }^{[1,18]}$ includes steps of checking the ventilator system; connections, humidifier, and monitoring ventilator parameters, alarms and changes in positive airway pressure or tidal volume, in addition to keeping ventilator tubing clear of condensation. Tube related care practices checklist ${ }^{[1]}$ includes firstly, verification of artificial airway placement through auscultation of lung sounds and verification of distal tip marking on ETT. Secondly, ensuring that the tube is internally (adequate cuff pressure 20-30 $\mathrm{cm} \mathrm{H}_{2} \mathrm{O}$ ) and externally fixed (using gauze or adhesive tape according to the unit policy) in place. Finally, place a biteblock in the patient's mouth if the patient is biting on the oral endotracheal tube.

Patient-related care practices checklist ${ }^{[1,18]}$ includes firstly, assessment; assessing airway patency, patient's alertness state and the ability to cooperate with the mechanical ventilator, patient-ventilator dyssynchrony, patient's need for administering sedation (according to agency policy), patient's respiratory status (symmetry of chest wall expansion, respiratory rate, depth, sputum production, lung sounds, and signs of hypoxia), patient's arterial blood gases results, vital signs, heart rhythm, heart sounds, central venous pressure (CVP), urine output and lower extremity edema, nutritional status, bowel sound, eye condition, oral mucosa integrity

Published by Sciedu Press and site of catheters, drains or lines. Secondly, interventions; airway interventions include ensuring adequate systemic hydration, nebulizing as physician's order, changing the patient's body position at least per $2 \mathrm{hrs,} \mathrm{performing}$ chest physiotherapy and removing secretions by suctioning. Nutrition-related interventions include providing enteral nutrition (well-balanced diet with low carbohydrate diet during weaning time). Skin-related interventions include applying skin care (ensure skin is kept clean and dry, apply the appropriate mattress, reposition the catheters, drains, and lines periodically), changing position, performing a range of motion exercises, encouraging independence and activity as tolerated by the patient. Communication to patient and family members (determine an appropriate way of communication). Other interventions include administration of suppositories and enemas as ordered, providing urinary catheter care, implement a comprehensive oral hygiene program, provide eye care (for unconscious patients, eyes are kept closed by taping/goggles, use of artificial tears, antibiotic drops or ointments) and psychologically, keep patient informed on progress and plans for weaning from the mechanical ventilator.

Each element of care was determined by the data collectors as a value-added (increase the form of the patient's service) or non-value added (doesn't add form of the patient's service or is not necessary) practice to the care process depending if one of the following waste which was derived from Womack and Jones model ${ }^{[1]}$ is existing: overproduction, waiting times, faults, excessive movement, not needed transport, excessive stocks, over-processing, and wasted talent. Time consumed for performing each care element by each critical care nurse was calculated and recorded.

Tool 2: Critical care nurses' self-report about waste during total care of mechanically ventilated patients

This tool was developed by the researchers after reviewing the related literature. ${ }^{[3,19]}$ This tool allows critical care nurses to report wastes in the following care categories; direct, indirect, personal and unit related care activities while caring for MVPs. A scale of 'Yes' or 'No' was utilized by nurses. Yes, if the waste is present and No, when the waste is absent. Wastes in each care category were in the form of cost, time or effort within the different three shifts. In addition, nurses' characteristics were a part of the tool such as sex, age, marital status, education level, job title, and years of ICU work experience.

\section{Tools validity and reliability}

The feasibility of the study design, validity, and readability of the tools assessed before conducting the study by five nursing expert professors in the critical care nursing, and 
in the nursing administration and by administrative staff in ICUs and the necessary modifications were done accordingly. A pilot study was carried out on ten percent of nursing staff for providing total care that was not be included in the study subjects $(\mathrm{N}=6)$ in order to check and ensure the clarity and applicability of the tools, identify obstacles and problems that may be encountered during data collection and the necessary modifications were carried out accordingly. Tool two was developed into the Arabic language. Reliability of tool one was 0.747 and tool two was 0.93 utilizing Alpha Cronbach test indicating accepted reliability.

\subsection{Study procedure}

The process of total care for MVPs was observed using tool one in which the value and non-value added care practices were determined. The care practice items were determined as a non-value added if any item adds cost, effort or time without adding value for the patient (waste). Before the start of the data collection, two research assistants from the Faculty of Nursing were trained by the researchers for a week in the two study settings using the study tools to assist in the data collection. Inter-rater reliability is exceeding $90 \%$.
Critical care nurses were observed while providing direct and indirect nursing care practices of MVPs along 24 hours by the researches and the assistant researches. Each nurse was observed three times at different three shifts (morning, evening, and night shifts), two researchers per shift in each ICU. The time consumed in performing each care item by the nurse was calculated by the data collector.

After observation, tool two was used to allow nurses to selfreport the wastes in each category of the total care for MVPs' practices in the form of cost, time or effort. The goal is to redesign the care process with a new process map that either minimize or completely eliminates the uncovered wastes that were self-reported by critical care nurses. The questionnaire was hand-delivered to the nurses in their settings at the break time. An interview was proceeded by the researchers and their assistants for 15-25 minutes for each nurse to complete the questionnaire. After that, an automated Lucid chart program designed units (see Figure 1), a flowchart diagram of the current MVPs' nursing care activities (see Figure 2), and VSM of the current care activities of the research study (see Figure 3) were developed by the researchers.
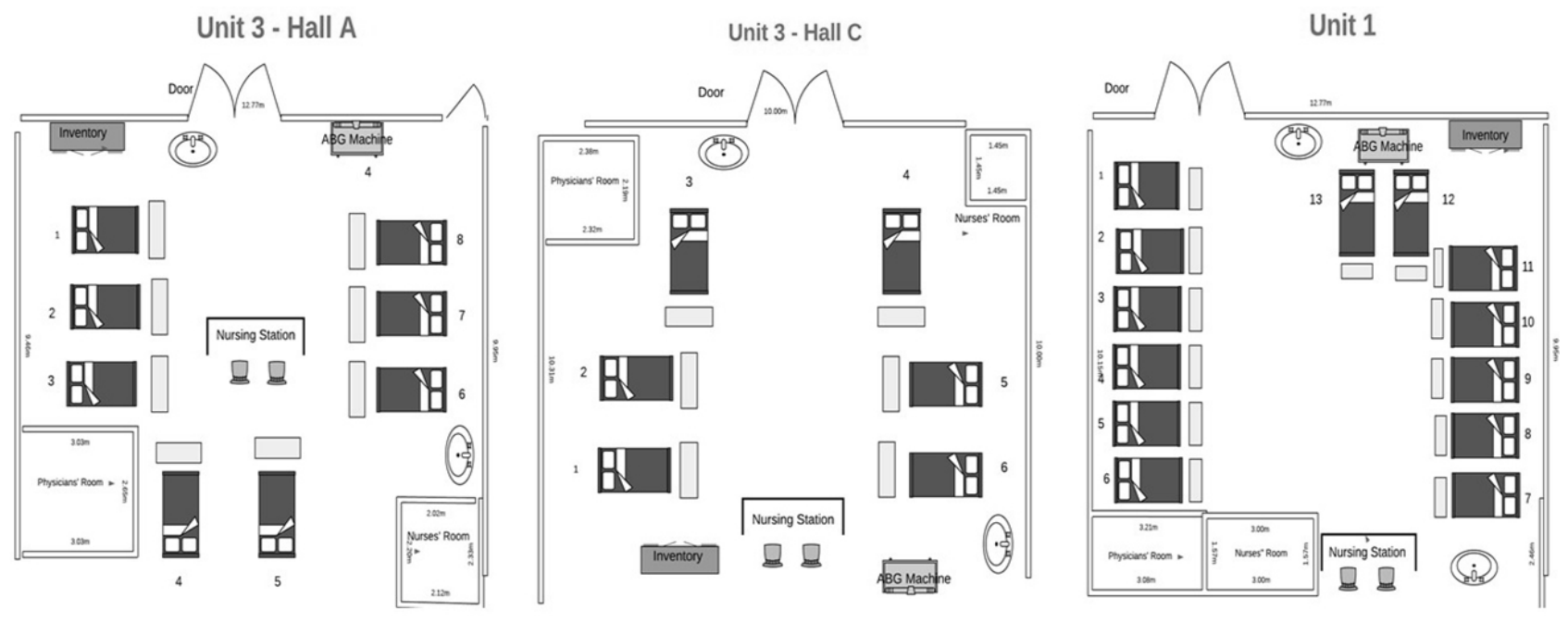

Figure 1. Research Study ICUs

\subsection{Administrative designs and ethical consideration}

An official letter including the aim and the setting of the study was obtained from the administrative authorities of the selected hospital to collect the data. Data were collected in a period of five months from the beginning of February 2018 to the end of June 2018. Nurses participated in the study were aware of its importance and then a witnessed informed consent was obtained from each nurse before participation in the study. Confidentiality, anonymity, and the right to participate, refuse or withdraw from the study at any time were guaranteed.

4

\subsection{Statistical analysis}

Data were fed to the computer and analyzed using IBM SPSS software package version 20.0. (Armonk, NY: IBM Corp). Quantitative data were described using a range (minimum and maximum), mean, and standard deviation. The significance of the obtained results was judged at the 5\% level. The used tests were chi-square test for categorical variables, to compare between different groups, Monte Carlo correction used for correction for chi-square when more than $20 \%$ of the cells have expected count and student $t$-test used for normally distributed quantitative variables, to compare between two studied groups. 


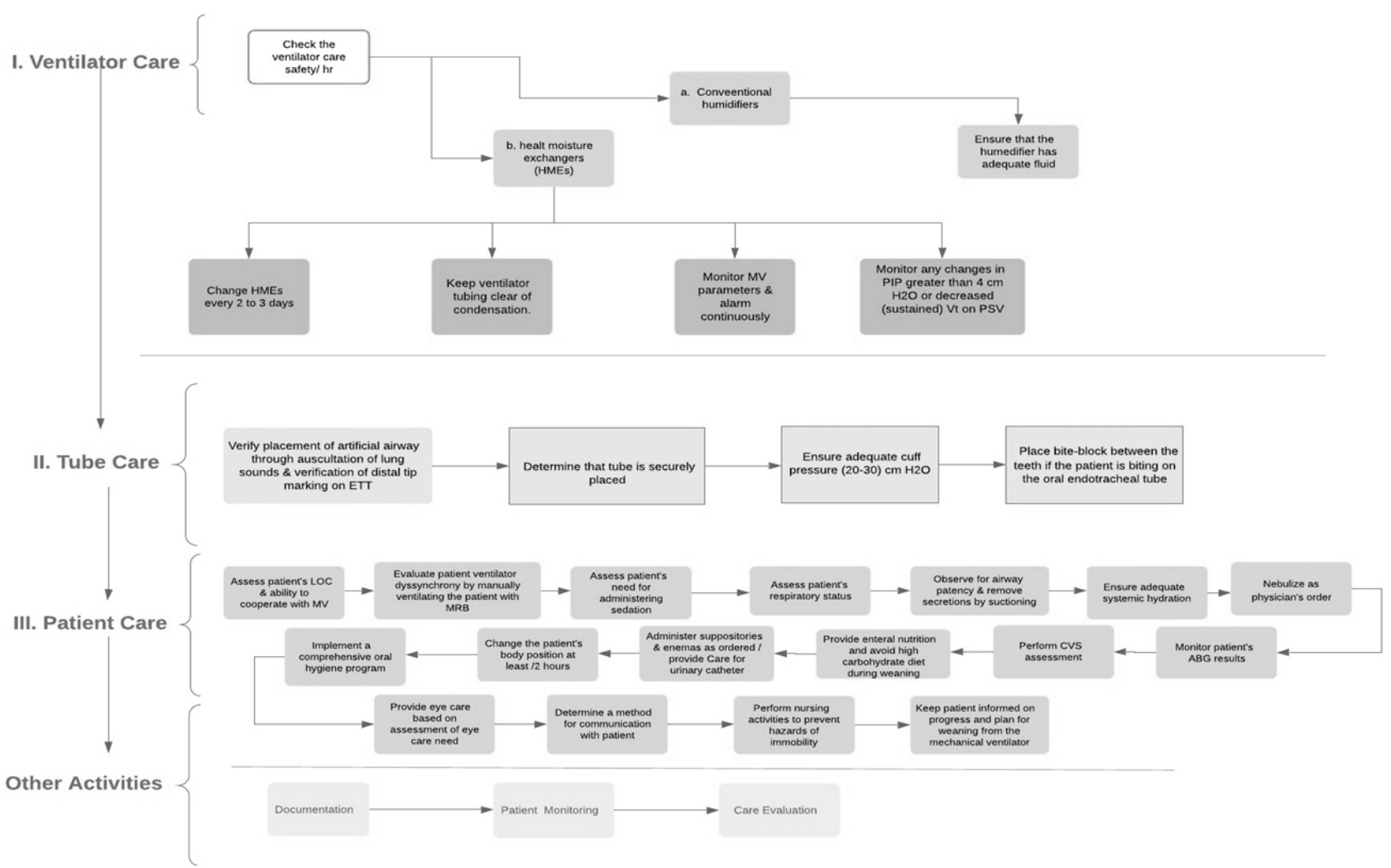

Figure 2. Mechanically Ventilated Patients' Total Care Flow

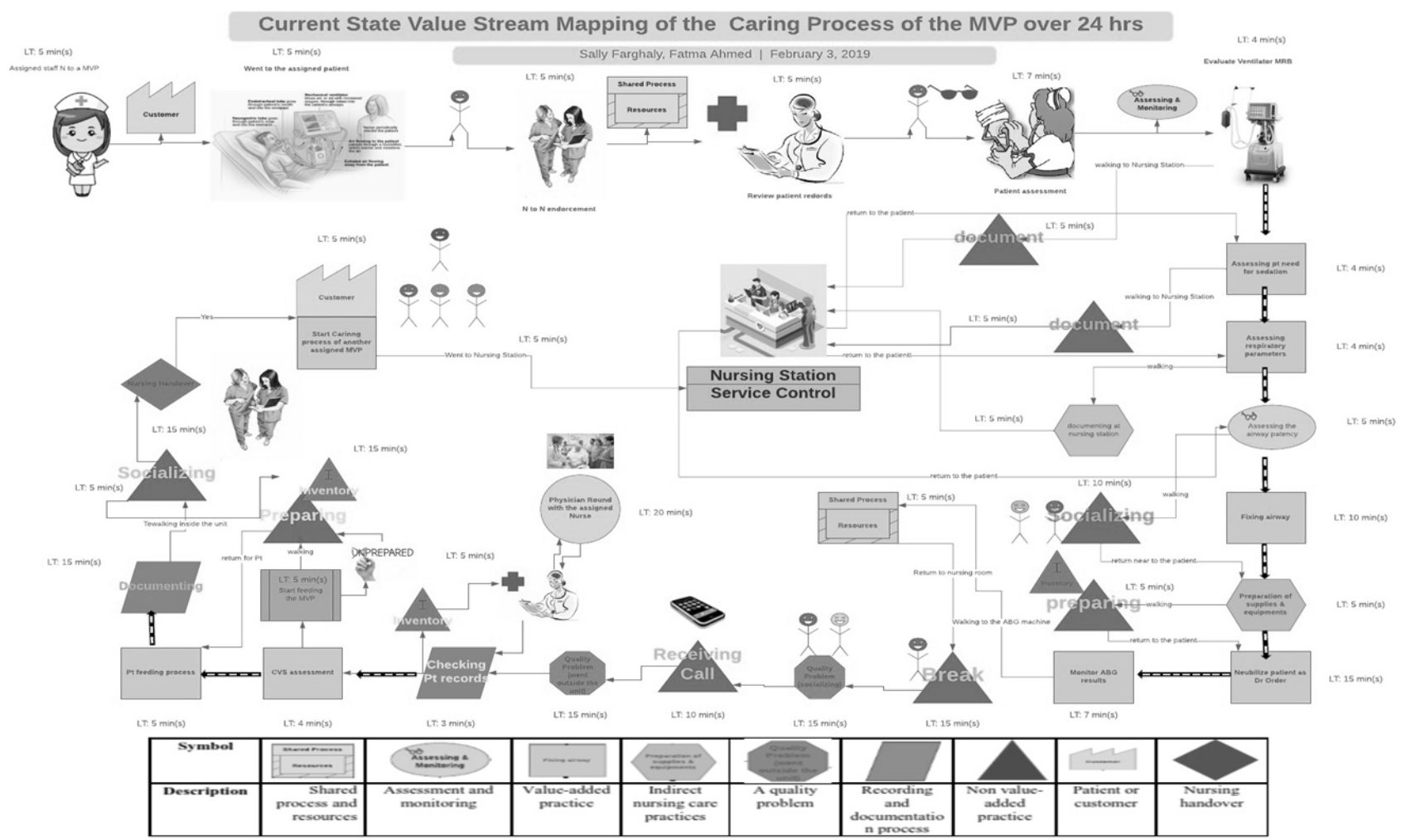

Figure 3. Current State Value Stream Mapping of the Caring Process of the MVP 


\section{RESUlts}

As shown in Table 1, more than $80 \%$ of nurses were females and $73.3 \%$ of them aged less than 30 years old. More than half of nurses $(61.7 \%)$ were single and living with their families $(65 \%) .70 \%$ of nurses had a nursing bachelor degree. The total work experience for more than half of nurses $(53.3 \%)$ was between 1 to 5 years, while the mean of department work experience (ICU) was $13.0 \pm 0.0$ years.

Table 1. Distribution of nurses according to their characteristics $(n=60)$

\begin{tabular}{|c|c|c|}
\hline Item & No. & $\%$ \\
\hline \multicolumn{3}{|l|}{ Gender } \\
\hline Female & 49 & 81.7 \\
\hline Male & 11 & 18.3 \\
\hline \multicolumn{3}{|l|}{ Age } \\
\hline$<30$ & 44 & 73.3 \\
\hline$\geq 30$ & 16 & 26.7 \\
\hline \multicolumn{3}{|l|}{ Marital status } \\
\hline Single & 37 & 61.7 \\
\hline Married & 23 & 38.3 \\
\hline Other & 0 & 0.0 \\
\hline \multicolumn{3}{|l|}{ Living condition } \\
\hline Living with families & 39 & 65.0 \\
\hline Living on their own & 1 & 1.7 \\
\hline Living with friends & 20 & 33.3 \\
\hline \multicolumn{3}{|l|}{ Educational degree } \\
\hline Diploma & 18 & 30.0 \\
\hline Technical Institute & 0 & 0.0 \\
\hline Bachelor & 42 & 70.0 \\
\hline \multicolumn{3}{|l|}{ Total work experience } \\
\hline$<1$ & 9 & 15.0 \\
\hline $1-<5$ & 32 & 53.3 \\
\hline $5-<10$ & 2 & 3.3 \\
\hline $10+$ & 17 & 28.3 \\
\hline \multicolumn{3}{|c|}{ Department work experience } \\
\hline Min.-Max. & 13.0 & \\
\hline Mean \pm SD & 13.0 & \\
\hline
\end{tabular}

From Table 2, it was shown that the differences between done and not done care practices in all items regarding the total care of MVPs were statistically significant $(p<.001)$. The differences between value added and non-value added care practice items were not statistically significant in ventilator and patient care practices items $(p=.232$ and .884$)$ respectively, while there was no statistical difference between the value added and non-value added care practice items in tube care.

The mean score of time consumed in patient care practices
$(5.89 \pm 3.56)$ was higher than the mean score of time consumed in ventilator and tube care practices $(2.91 \pm 3.76$, and $2.37 \pm 1.22$ ) respectively. The differences between the time consumed in all care practices items were statistically significant $(p<.001)$ (see Table 3$)$.

According to the nurses' self-report, direct care for MVPs was ranked as the first care category that can increase the cost and effort with mean \pm SD $90.56 \pm 23.04$ and 100.0 \pm 0.0 respectively. The indirect patient care constitutes the second order in wasting the cost and effort with mean \pm SD $8.33 \pm 13.20$ and $86.94 \pm 25.32$ respectively as reported by nurses. The unit related activities constitute the last activities wasting the nurses' time while caring for MVPs with mean \pm SD $88.06 \pm 21.72$. Personal activities of nurses form the second cause of wasting their time $(95.83 \pm 15.38)$ while they did not contribute to increase the cost of care $(1.25 \pm 9.68)$, however, these activities contribute to increase the effort for some nurses with mean \pm SD $69.17 \pm 32.67$. Documentation process was self-reported by the majority of nurses $(98.33 \pm 7.33)$ as a time waste process (see Table 4$)$.

\section{Discussion}

The main goal of healthcare system is to provide a high quality of care to everybody by improving the services, reducing variations in care, and eliminating the non-value add activities in order to achieve patients' satisfaction. ${ }^{[20]}$ Therefore, this study concerned with evaluating the added and non-value added practices of the total care of MVPs. The current study results indicate that the differences between done and not done care practices by nurses of the total care of MVPs were statistically significant. Through observation, the not done care practices (missed care activities based on the care standards of the MVPs) were in the form of assessing level of consciousness, and assessing MVPs' need for oral care. This may be due to the increased nursing workload with a low nurse-to-patient ratio in the study settings, limited materials, and supplies needed for the accomplishment of the care activities, poor communication between the staff, too many tasks to be done for MVPs in the same time and lack of continuous supervision.

This study results are in line with a study done by Ball et al. $(2014)^{[21]}$ to examine the nature and prevalence of care left undone by nurses in English National Health Service hospitals, the researchers found that most nurses working on ICUs reported that some care was left undone on their shifts.

Additionally, Ball et al. showed that nurses were more likely to report care being left undone (or 'missed') when they are working on shifts with high numbers of patients per nurse. 
Table 2. Distribution of nurses according to value and non-value added care practices for MVPs

\begin{tabular}{|c|c|c|c|c|}
\hline \multirow{4}{*}{ Care practices } & \multicolumn{3}{|c|}{ \% Practice score $(n=60)$} & \multirow{4}{*}{$t\left(p_{1}\right)$} \\
\hline & \multirow{2}{*}{$\begin{array}{l}\text { Not done } \\
\text { (missed) }\end{array}$} & \multicolumn{2}{|l|}{ Done } & \\
\hline & & Non added & Added & \\
\hline & Mean \pm SD & Mean \pm SD & Mean \pm SD & \\
\hline Ventilator Care & $22.86 \pm 10.13$ & $50.0 \pm 10.10$ & $55.71 \pm 10.54$ & $10.698^{*}\left(<.001^{*}\right)$ \\
\hline$t\left(p_{2}\right)$ & & $1.238(.232)$ & & \\
\hline Tube care & $16.17 \pm 15.40$ & $40.0 \pm 0.0$ & $40.0 \pm 0.0$ & $10.608^{*}\left(<.001^{*}\right)$ \\
\hline$t\left(p_{2}\right)$ & & - & & \\
\hline Patient care & $26.44 \pm 10.75$ & $45.26 \pm 5.08$ & $45.61 \pm 5.26$ & $9.319^{*}\left(<.001^{*}\right)$ \\
\hline$t\left(p_{2}\right)$ & & $0.148(.884)$ & & \\
\hline
\end{tabular}

Table 3. Time consumed by nurses in total care practices for mechanically ventilated patients

\begin{tabular}{|c|c|c|c|c|c|c|c|}
\hline \multirow{3}{*}{ Care practices } & \multicolumn{6}{|c|}{ Time } & \multirow{3}{*}{$\chi^{2}\left({ }^{\mathrm{MC}} p\right)$} \\
\hline & \multicolumn{2}{|r|}{$<5$} & \multirow{2}{*}{$\begin{array}{l}5-10 \\
\text { No. (\%) }\end{array}$} & \multirow{2}{*}{\begin{tabular}{|l}
$10-15$ \\
No. $(\%)$
\end{tabular}} & \multirow{2}{*}{$\begin{array}{l}15-20 \\
\text { No. (\%) }\end{array}$} & \multirow{2}{*}{$\begin{array}{l}\geq 20 \\
\text { No. (\%) }\end{array}$} & \\
\hline & Mean \pm SD & No. (\%) & & & & & \\
\hline Ventilator Care & $2.91 \pm 3.76$ & $16(80.0)$ & $3(15.0)$ & $1(5)$ & $0(0.0)$ & $0(0.0)$ & $\begin{array}{l}48.026^{*} \\
\left(<.001^{*}\right)\end{array}$ \\
\hline Tube care & $2.37 \pm 1.22$ & $11(84.6)$ & $2(15.4)$ & $0(0.0)$ & $0(0.0)$ & $0(0.0)$ & $\begin{array}{l}34.761^{*} \\
\left(<.001^{*}\right)\end{array}$ \\
\hline Patient care & $5.89 \pm 3.56$ & $13(68.4)$ & $3(15.8)$ & $1(5.3)$ & $1(5.3)$ & $0(0.0)$ & $\begin{array}{l}31.600^{*} \\
\left(<.001^{*}\right)\end{array}$ \\
\hline
\end{tabular}

Note. $\chi^{2}$ : Chi square test; MC: Monte Carlo; ${ }^{*} p \leq .05$

Table 4. Mean percentage of nurses' self-report regarding the waste outcomes

\begin{tabular}{|c|c|c|c|c|c|c|}
\hline \multirow{3}{*}{ Care practices } & \multicolumn{6}{|c|}{ Waste outcomes } \\
\hline & \multicolumn{2}{|l|}{ Cost } & \multicolumn{2}{|l|}{ Time } & \multicolumn{2}{|l|}{ Effort } \\
\hline & Mean \pm SD. & Rank & Mean \pm SD. & Rank & Mean \pm SD. & Rank \\
\hline Direct care & $90.56 \pm 23.04$ & 1 & $93.89 \pm 17.88$ & 3 & $100.0 \pm 0.0$ & 1 \\
\hline Indirect care & $8.33 \pm 13.20$ & 2 & $93.89 \pm 15.33$ & 3 & $86.94 \pm 25.32$ & 2 \\
\hline Unit related activities & $3.33 \pm 9.10$ & 4 & $88.06 \pm 21.72$ & 5 & $77.50 \pm 29.56$ & 3 \\
\hline Personal activities & $1.25 \pm 9.68$ & 5 & $95.83 \pm 15.38$ & 2 & $69.17 \pm 32.67$ & 4 \\
\hline Documentation & $4.44 \pm 18.88$ & 3 & $98.33 \pm 7.33$ & 1 & $58.33 \pm 41.45$ & 5 \\
\hline Overall & $16.36 \pm 6.49$ & & $93.26 \pm 11.67$ & & $79.02 \pm 17.56$ & \\
\hline
\end{tabular}

To improve nurse competencies, performance appraisals use institutionally developed criteria in addition, it usually conducted through communication with managers, peer review, and self-assessment of performance. For this purpose, the nurse value added (NVA) approach was applied to performance measurement and compensation enhancement models. This approach is more desirable, producing individualized nurse performance assessments, and has been associated with improved patient outcomes. ${ }^{[22-25]}$ In the current study findings, it was found that the differences between value added and non-value added nursing care practices were not statistically significant in ventilator and patient care related prac- tices items, while there was no statistical difference between the value added and non-value added care practice items in tube care. The results of the current study are in contrast with many studies. As Yakusheva, et al. (2014), ${ }^{[26]}$ Aiken et al. (2014) ${ }^{[27]}$ and Rothman et al. (2012) ${ }^{[28]}$ who found in their studies which aimed mainly to estimate the NVA practices to patients' clinical condition change in the acute care setting that a significant correlation in NVA between the study subjects, indicating that the staff nurse effects were persistent and nurse-specific.

The present study results revealed also that the mean score 
of time consumed in patient care was higher than the mean score of time consumed in ventilator and tube care practices. The differences between the time consumed in each care practice items were statistically significant. In addition, nurses reported that the unit related activities, personal activities and documentation process waste their time in the morning shift was higher than evening and night shifts. While, the direct care activities of MVPs ranked as the first care category that can increase the cost and effort. This may be related to inappropriate stocked par levels for supplies as it was the main cause of the time waste. In addition, access to other departments, supply inventory room, and the availability of clerical and nursing staff were limited in the study settings and ICUs administrative authorities continue to operate on the false assumptions that nurses can provide care when there are scarce hospital resources that do not operate on a 24-hour, 7-daycare cycle. Another major driver of time and cost was hand-offs, including shift report and patient transfers and discharges.

These results are in congruent with a study conducted by Butts and Rich (2013) ${ }^{[29]}$ to develop a reliable instrument to measure the acute care nurse practitioners' activities, they found that the components of direct care appear to be at the top of the most frequently performed activities in the acute care settings. Moreover, acute care nurse practitioners state that they were spending the most time in assessment, admitting a patient, and taking history and performing a physical examination, which is the predominant direct care activity which constitutes about one-third of their workweek followed by the indirect care activities. The study findings are in line also with Blay, Duffiel, Gallagher and Roche $(2014)^{[30]}$ who discussed in a study the non-value add costs of acute care unit nursing activities, and the amount of valueadded versus NVA time for each activity. They found that ICUs followed the medical-surgical units in relation to the amount of NVA time in nursing activities as well as the average annual non-value-added wage costs. Additionally, they added that the drivers of the NVA time were related to searching for working equipment, lack of access to sufficient supplies, locating other care providers and support staff (eg, pharmacists, laboratory, radiology, transporters), and hand-offs. Jimmerson (2017), ${ }^{[31]}$ revealed that work system failures were responsible for high amounts of waste in hospital nursing that involved medications, orders, supplies, staffing, and equipment.

Also, Arnold and Valentin, (2013) ${ }^{[32]}$ agreed with the current study results as they found that although nurses generally perceived that they should not utilize social networking while they are at work, they do not care that much, and are doing it anyway. While they continue to use social networking in the workplace even if they know they should not.

A value stream map has been used widely as an important tool to study the patient flow in the critical care units by calculating the value added, non-value added, and lead time to care the patients as well as the service provided in that units. ${ }^{[33]}$ The current study findings revealed that the majority of causes for non-value added activities and missed care practices were due to poor knowledge and skills regarding most of the ICU procedures' techniques (the standardized care practices), improper resources utilization due to high nurses' workload, poor monitoring and supervision, incompetent staff nurses, unmotivated staff nurses and high level of burnout as they did the due care with minimal efforts ignoring adherence to the standardized guidelines for procedures, and ineffective communication with the patient and other health care providers. However, the cost spent in nursing wages annually in each ICU for wasted nursing time could be reduced dramatically by concentrating on system changes, which would increase both nursing workload capacity and job satisfaction. Further analysis of shift differences in costs and activity recommend meeting the challenges of future care delivery to improve the efficiency of the care.

\subsection{Implications for clinical practice}

- Specific attention should be paid to lean introduction in acute care settings.

- Preliminary gap analysis to the patients' actual care (lean evaluation) should be performed to identify the value and non-value added care practices.

- Lean techniques should be used to improve the efficiency, safety, clinical outcomes, and satisfaction for MVPs and ultimately to reinforce economic performance.

- A value stream map is a lean strategy that should be used to guide nurses to implement the steps that add value while caring for MVPs without taking up resources and time.

\subsection{Study limitations}

This study presents a novel approach to assessing value added and non-value added activities in relationship with MVPs care process. Unmeasured variables make our estimates conservative. NVA improvement plan and human capital would likely continue to be an important determinant of outcomes in future studies that have access to more variables. We hope that this approach serves as the basis for future studies using different samples, outcomes, and controls so that the validity of the lean approach and generalizability of our results to other hospitals and work environments can be assessed. 


\section{Conclusion}

Applying lean strategies in ICUs need firstly to continuous analysis and evaluation of all steps of the care to filtrate the components of care to value-added and non-value-added practices. The study results indicated that there was a statistical significant difference between the done and missed (not done) care practices. Not all care practices for MVPs have been added value to the patients, however, there was no statistical significant difference between the value added and non-value added practices. Waste outcomes as self-reported by nurses enrolled in this study revealed that direct care was mostly associated with cost waste with increasing their efforts. While documentation process as reported by most of them has been waste the time of care.

\section{Recommendations}

In view of future attempts to introduce lean in critical care and based on the concept of creating value-added care prac- tices, lean in ICUs need to be acknowledged. Critical care nurses should eliminate the non-value added care practices of total care for MVPs. Standardization of a continuous flow of care for MVPs with minimal delays should be developed and followed by critical care nurses in the study settings. Organizational development, lean principles, quality improvement, and value chain management, are disciplines that must aggregate into nursing curricula to prepare novice nurses for the lean work in ICUs. Continuous lean in-service training educational programs should be provided for critical care nurses. In addition, quality improvement policies to support the lean management in ICUs and eliminate all types of wastes should be available and followed.

\section{CONFLicts OF INTEREST Disclosure}

The authors declare that there is no conflict of interest.

\section{REFERENCES}

[1] Morton PG, Fontaine DK. Critical care nursing: a holistic approach. 2017; 525-539.

[2] D'Andreamatteo A, Ianni L, Lega F, et al. Lean in healthcare: A comprehensive review. Health policy. 2015; 119(9): 1197-1209. PMid:25737260 https://doi.org/10.1016/j.healthpol.20 15.02 .002

[3] Hallam CR, Contreras C. Lean healthcare: scale, scope and sustainability. International Journal of Health Care Quality Assurance. 2018 Aug 13; 31(7): 684-96. PMid:30354875 https://doi.org/10.1 108/IJHCQA-02-2017-0023

[4] Sirvent J, Gil M, Alvarez T, et al. Lean techniques to improve flow of critically ill patients in a health region with its epicenter in the intensive care unit of a reference hospital. Medicina Intensiva (English Edition). 2016; 40(5): 266-272. https ://doi .org/10.101 $6 / j$.medine .2015 .08 .007

[5] Anesi GL, Wagner J, Halpern SD. Intensive Care Medicine in 2050: toward an intensive care unit without waste. 2017.

[6] Trzeciak S, Mercincavage M, Angelini C, et al. Lean Six Sigma to reduce intensive care unit length of stay and costs in prolonged mechanical ventilation. Journal for Healthcare Quality. 2018; 40(1): 36-43. PMid:27902532 https://doi.org/10.1097/JHQ.0000000000 000075

[7] Magalhães ALP, Erdmann AL, Silva ELD, et al. Lean thinking in health and nursing: an integrative literature review. Revista Latino-Americana de Enfermagem. 2016. PMid:27508906 https : //doi.org/10.1590/1518-8345.0979.2734

[8] Gershengorn HB, Kocher R, Factor P. Management strategies to effect change in intensive care units: lessons from the world of business. Part II. Quality-improvement strategies. Annals of the American Thoracic Society. 2014; 11(3): 444-453. PMid:24601668 https://doi.org/10.1513/AnnalsATS . 201311-392AS

[9] Teich ST, Faddoul FF. Lean management - the journey from Toyota to healthcare. Rambam Maimonides Medical Journal. 2013; 4(2). PMid:23908857 https://doi.org/10.5041/RMMJ 10107
[10] Poksinska B, Swartling D, Drotz E. The daily work of Lean leaderslessons from manufacturing and healthcare. Total Quality Management \& Business Excellence. 2013; 24(7-8): 886-898. https : //doi.org/10.1080/14783363.2013.791098

[11] Guizzi G, Chiocca D, Romano E. Healthcare lean thinking: simulation of an intensive care unit (ICU). Paper presented at the Advances in Computer Science, Proceedings of the 6th WSEAS European Computing Conference (ECC '12). 2012.

[12] Ravi P, Vijai M. Errors in ICU: how safe is the patient? A prospective observational study in a tertiary care hospital. J Anesth Clin Res. 2015; 6(6): 535.

[13] Albanese CT, Aaby DR, Platchek TS. Advanced lean in healthcare: CreateSpace Independent Publishing Platform. 2014.

[14] Lina AQ, Abdallah AA, Salam SZ. Six Sigma Application in Healthcare Logistics: A Framework and A Case Study. Journal of Healthcare Engineering. 2019. PMid:30906516 https ://doi .org/10.1 155/2019/9691568

[15] Terra JDR, Berssaneti FT. Application of lean healthcare in hospital services: a review of the literature (2007 to 2017). 2018.

[16] Henriques JF, Caseiro R, Martins P, et al. High-speed tracking with kernelized correlation filters. IEEE Transactions on Pattern Analysis and Machine Intelligence. 2015; 37(3): 583-596. PMid:26353263 https://doi.org/10.1109/TPAMI . 2014.2345390

[17] Pieńkowski M. Waste measurement techniques for Lean companies International Journal of Lean Thinking. 2015; 5(1): 9-24.

[18] Kamio T, Masamune K. Mechanical Ventilation-Related Safety Incidents in General Care Wards and ICU Settings. Respiratory Care. 2018; 63(10): 1246-1252. PMid:29844212 https ://doi.org/10 $.4187 /$ respcare.06109

[19] Antinaho T, Kivinen T, Turunen H, et al. Nurses' working time use-how value adding it is? Journal of Nursing Management. 2015; 23(8): 1094-1105. PMid:25280350 https://doi.org/10.1111/ jonm. 12258

[20] Thangarajoo Y, Smith A. Lean thinking: An overview. Industrial Engineering \& Management. 2015; 4(2): 2169-0316. 
[21] Ball JE, Rafferty AM, Morrow E, et al. Care left undone'during nursing shifts: associations with workload and perceived quality of care. BMJ Qual Saf. 2014; 23(2): 116-125. PMid:23898215 https ://doi.org/10.1136/bmjqs-2012-001767

[22] Weathers SM, Raleigh EDH. 1-Year retention rates and performance ratings: comparing associate degree, baccalaureate, and accelerated baccalaureate degree nurses. Journal of Nursing Administration. 2013; 43(9): 468-474. PMid:23958525 https://doi.org/10.1 097/NNA . 0b013e3182a23d9f

[23] Stonehouse W, Conlon CA, Podd J, et al. DHA supplementation improved both memory and reaction time in healthy young adults: a randomized controlled trial. The American of Clinical Nutrition. 2013; 97(5): 1134-1143. PMid:23515006 https://doi.org/10 $.3945 / a j c n .112 .053371$

[24] Kaplow L. An optimal tax system. Fiscal Studies. 2011; 32(3): 415-435. https ://doi.org/10.1111/j.1475-5890.20 $11.00144 . \mathrm{x}$

[25] Kendall-Gallagher D, Aiken LH, Sloane DM, et al. Nurse specialty certification, inpatient mortality, and failure to rescue. Journal of Nursing Scholarship. 2011; 43(2): 188-194. PMid:21605323 https://doi.org/10.1111/j.1547-5069.2011.01391.x

[26] Yakusheva O, Lindrooth R, Weiss M. Economic evaluation of the $80 \%$ baccalaureate nurse workforce recommendation: a patient-level analysis. Medical Care. 2014; 52(10): 864-869. PMid:25215646 https://doi.org/10.1097/MLR.0000000000000189
[27] Aiken LH, Sloane DM, Bruyneel L, et al. Nurse staffing and education and hospital mortality in nine European countries: a retrospective observational study. The Lancet. 2014; 383(9931): 1824-1830. https://doi.org/10.1016/S0140-6736(13)62631-8

[28] Rothman MJ, Solinger AB, Rothman SI, et al. Clinical implications and validity of nursing assessments: a longitudinal measure of patient condition from analysis of the Electronic Medical Record. BMJ Open. 2012; 2(4): e000849. PMid:22874626 https ://doi.org/10.1136/bmjopen-2012-000849

[29] Butts JB, Rich KL. Philosophies and theories for advanced nursing practice. Jones \& Bartlett Publishers; 2013 Dec 26.

[30] Blay N, Duffield CM, Gallagher R, et al. A systematic review of time studies to assess the impact of patient transfers on nurse workload. International Journal of Nursing Practice. 2014 Dec; 20(6): 662-73. PMid:24689656 https ://doi.org/10.1111/ijn. 12290

[31] Jimmerson C. Value stream mapping for healthcare made easy. Productivity Press; 2017 Jul 26. https : //doi .org/10.1201/b10247

[32] Arnold DG, Valentin A. Corporate social responsibility at the base of the pyramid. Journal of Business Research. 2013; 66(10): 1904-1914. https://doi.org/10.1016/j.jbusres.2013.02.012

[33] Martin K, Osterling M. Value stream mapping: how to visualize work and align leadership for organizational transformation. New York, NY: McGraw-Hill. 2014. 